\title{
Neural stem cells transplantation in cortex in a mouse model of Alzheimer's disease
}

\author{
Qinghua Wang, Yoshihito Matsumoto, Tokuhisa Shindo, Keisuke Miyake, Atsushi Shindo, \\ Masahiko Kawanishi, Nobuyuki Kawai, Takashi Tamiya, and Seigo Nagao \\ Department of Neurological Surgery, Faculty of Medicine, Kagawa University, Kagawa, Japan
}

\begin{abstract}
Objective. The goal of this study was to elucidate the effect of neurospheres (NS) on dementia in the mouse model of nucleus basalis of Meynert (NBM) lesion.

Methods. Mouse embryonic stem cell (ES) derived neurospheres were transplanted into the frontal association cortex and barrel field of S1 cortex of C57BL/6 mice 4 weeks after including a lesion of NBM by ibotenic acid, while other healthy mice that received ES cells served as control. Behavioral tests by 8-arm radial maze were conducted 8 weeks after transplantation, and double staining of choline acetyltransferase (ChAT), serotonin, amyloid- $\beta$ protein (AP) and green fluorescent protein (GFP) 12 weeks after transplantation. We found that the neurospheres transplanted into the mouse cortex survived and produced many ChAT-positive neurons and a few serotoninpositive neurons in and around the grafts. The working memory error decreased significantly in the mice grafted with neurospheres. In contrast, the ES cells developed into teratomas in all of the control mice and expressed no neurons, and the working memory deteriorated remarkably.

Conclusions. Transplantation of neurospheres, but not ES cells, into the prefrontal and parietal cortices, dramatically alleviated the cholinergic deficits and recent memory disruption in the NBM lesioned mice. J. Med. Invest. 53 : 61-69, February, 2006
\end{abstract}

Keywords : neurosphere, embryonic stem cell, nucleus basalis of Meynert, dementia, mouse

\section{INTRODUCTION}

Alzheimer's disease (AD) is the most common form of degenerative dementia that affects a large proportion of the elderly people with initial and progressive symptoms of memory loss (1-3). The most consistent findings in $\mathrm{AD}$ are degeneration of the cholinergic cells in the nucleus basalis of Meynert (NBM) and loss of the basal forebrain cortical cholinergic innervation (4). Clinical studies have suggested that the loss of cholinergic axons

Abbreviations : $\mathrm{AD}=\mathrm{Al}$ zheimer's disease; $\mathrm{ChAT}=$ choline acetyltransferase ; $\mathrm{ANOVA}=$ analysis of variance ; $\mathrm{AP}=$ amyloid- $\beta$ protein ; $\mathrm{ES}=$ embryonic stem cell; $\mathrm{GAD}=$ glutamate decarboxylase; $\mathrm{GFAP}=$ glial fibrillary acidic protein; GFP=green fluorescent protein ; GMEM=Glasgow minimal essential medium ; $\mathrm{HE}=$ hematoxylin and eosin;LIF=leukemia inhibitory factor; LSM=laser scanning microscope ; NBM=nucleus basalis of Meynert; $\mathrm{NPCs}=$ neural progenitor cells $; \mathrm{NSCs}=$ neural stem cells, $\mathrm{PD}=$ Parkinson's disease. may contribute to the cognitive deficits in $\mathrm{AD}$. The major cholinergic innervation to the cerebral cortex originates from NBM. The pathological hallmarks of $\mathrm{AD}$ are extracellular deposition of amyloid- $\beta$ protein (AP) senile plaques, and intracellular accumulation of neurofibrillary tangles containing an abnormally phosphorylated microtubule-associated protein, tau (5). It is believed that the above-mentioned neuropathological alterations affecting mainly the cholinergic system cause dementia in $\mathrm{AD}$ patients. The currently available therapeutic interventions mainly aim at

Received for publication September 5, 2005 ; accepted November 28, 2005.

Address correspondence and reprint requests to Qinghua Wang, Department of Neurological Surgery, Faculty of Medicine, Kagawa University, 1750-1 Ikenobe, Miki-cho, Kita-gun 761- 0793, Kagawa, Japan and Fax : +81-87-891-2208. 
alleviating the cholinergic deficits, but unfortunately, these strategies do not prevent the disease, but instead offer a limited symptomatic improvement (6).

Identification of the mammalian neural stem cells (NSCs) has brought high expectations for the clinical application of NSCs in the cell replacement therapeutic procedures for the central nervous system disorders. Recent studies have demonstrated that transplantation of in vitro expanded neural progenitor cells (NPCs) including NSCs in the animal models of several neurological conditions, such as Parkinson's disease (PD), multiple sclerosis, traumatic and ischemic brain injuries, resulting in functional recovery of the animals to some extent (7-12). These data suggest that such neural precursors might offer a useful future therapy for $\mathrm{AD}$. The embryonic stem cells (ES cells) were first isolated from cultures of the mouse blastocysts approximately two decades ago (8). The ES cells give rise to aggregates of cells that are termed embryoid bodies (EBs). The EBs can change into various cell types that are descendants of the three cardinal germ layers of the embryo. Selective expansion of NSCs by culture of the EBs in serum-free defined media with fibroblast growth factor-2 (FGF-2) allows further elaboration of neurospheres that can be specified to become neurons by application of FGF-2 $(11,12)$.

In the present study, we tried to assess whether the mouse embryonic stem cell(ES)-derived neurospheres grafted in the prefrontal and parietal cortices have effects on the disruption of spatial memory and the impaired histology of the cholinergic system after including a lesion in NBM.

\section{MATERIALS AND METHODS}

\section{Animals}

The experimental protocol was approved by the Institute of Laboratory Animal Sciences of Faculty of Medicine of Kagawa University and conforms to the National Institutes of Health guidelines for the care and use of animals in research. 9-week-old adult male C57 $\mathrm{BL} / 6$ mice weighing 20 to $22 \mathrm{~g}$ were used for all experiments.

\section{Experimental design}

Five groups of mice were used for behavioral and histological studies (1). NS transplantation group: mice $(n=10)$ received neurospheres transplantation 4 weeks after NBM lesion (2). ES transplantation group: mice $(\mathrm{n}=6)$ received mouse embryonic stem cells (ES) transplantation 4 weeks after NBM lesion(3). Lesioned group:mice $(\mathrm{n}=14)$ were lesioned in the right NBM (4). Sham lesioned control group:mice $(n=12)$ were given injection of vehicle $(0.1 \mu \mathrm{l}$ of $0.1 \mathrm{mmol} \mathrm{PBS})$ (5). Normal control group : age-matched mice $(n=15)$ received no manipulations were served as normal controls.

\section{NBM lesioning}

Animals were anesthetized using a combination of ketamine ( $60 \mathrm{mg} / \mathrm{kg}$ body weight; Bayer, Germany) and xylazine (20mg/kg body weight; Bayer, Germany) in saline administered intraperitoneally. After being fixed carefully in stereotaxic apparatus (Model SR$6 \mathrm{~N}$, Narishige, Japan), the mouse's scalp was cut, a small craniotomy was drilled, and $0.5 \mu \mathrm{g}$ ibotenic acid in $0.1 \mu \mathrm{l}$ of $0.1 \mathrm{mmol}$ phosphate-buffered saline (PBS) was infused into each of two sites of right NBM (13) (coordinates from bregma, midline, and dura, with incisor bar+1: $\mathrm{A}=-0.1, \mathrm{~L}=2.0, \mathrm{DV}=4.2 ; \mathrm{A}=-0.8, \mathrm{~L}=2.5$, $\mathrm{DV}=4.0$ respectively through a glass capillary (inner diameter $\sim 50 \mu \mathrm{m})$ connected to a $2-\mu \mathrm{l}$ Hamilton syringe (Model 7102KH, Reno, NV). The infusion was made over 3 minutes, retained 3 minutes, and retarded 3 minutes.

\section{Neural stem cell culture}

ES cell culture Mouse ES cell lines EB3 which has one allele of Pou5f1 inactivated by targeted integration of an IRESBSDpA cassette and transfected with GFP gene were cultivated as described previously (14). Briefly, the cells were maintained in the absence of feeder cells in Glasgow minimal essential medium (GMEM ; Sigma) supplemented with 10\% FCS (EquitechBio Inc, Kerrville, TX), $1 \mathrm{mM}$ sodium pyruvate, $10^{-4} \mathrm{M}$ 2-mercaptoethanol, $1 \times$ nonessential amino acids, and 1,000 $\mathrm{U}$ of leukemia inhibitory factor (LIF) per ml on gelatin-coated dishes. $5 \mu \mathrm{g} / \mathrm{ml}$ of blastcydineS (Funakoshi, Tokyo, Japan) was further added for the stem cell selection.

\section{Differentiation of ES cells and selective amplification and differentiation of neural progenitor cells}

To induce differentiation of ES formation, a single cell suspension of ES cells were plated onto nonadeherent bacterial culture dishes at a density of $5 \times 10^{4}$ cell/ml in $\alpha \mathrm{MEM}$ (GIBCO/Invitrogen) supplemented with $10 \% \mathrm{FCS}, 10^{-4} \mathrm{M}$ 2-mercaptoethanol. After EBs formation 6 days later, a single suspension were got by trypsinization for 5 minutes with $0.25 \%$ trypsin in $1 \mathrm{mM}$ EDTA (GIBCO/Invitrogen), followed by quenching with $10 \%$ FCS. The cells were washed 
twice with basic neurosphere medium composed of DMEM:F12 (1:1), 0.6\% glucose, $2 \mathrm{mM}$ glutamine, $3 \mathrm{mM}$ sodium bicarbonate, $5 \mathrm{mM}$ HEPES buffer, $25 \mu \mathrm{g} /$ $\mathrm{ml}$ insulin, $100 \mathrm{\mu g} / \mathrm{ml}$ transferring, $20 \mathrm{nM}$ progesterone, $60 \mu \mathrm{m}$ putrescine, $30 \mathrm{nM}$ selenium chloride ( all from Sigma except glutamine from GIBCO/Invitrogen) and plated onto T75 flasks (Greiner) at a density of $2 \times 10^{4}$ or $1 \times 10^{5}$ cells $/ \mathrm{ml}$ in the neurosphere medium basic neurosphere medium supplemented with $20 \mathrm{ng} /$ ml FGF 2 (Peprotech, Rocky Hill, NJ) and $2 \mu \mathrm{g} / \mathrm{ml}$ heparin sulfate (Sigma). Cells were grown for 5 to 7 days and formed neurospheres. For in vitro differentiation of NPCs, the neurospheres were plated onto poly-L-ornithin coated dishes in the basic neurosphere medium and cultured for 5 to 14 days (P0).

ES cells were taken for transplantation 3 days after monolayer formation of ES and neurospheres 5 to 7 days of $\mathrm{P} 0$ neurospheres. ES cells were collected by centrifugation at $800 \mathrm{rpm}$ for 3 and resuspended in the ES culture medium. NS cells were collected by settling down for 15 minutes and resuspended in the NS culture medium. Cell suspensions were made at a density of $1-5 \times 10^{4}$ cells $/ \mu$ land were kept on ice to optimize cell viability.

\section{Transplantation}

Transplantation was conducted 4 weeks after NBM lesion when the animals had recovered from the surgery and cholinergic deafferentation was complete (data note shown). ES or NS cells were transplanted to regions of frontal association cortex and barrel field of S1 cortex stereotaxically. Glass capillary (inner diameter $\sim 70 \mu \mathrm{m}$ ) connected to a $2-\mu 1$ Hamilton syringe (Model $7102 \mathrm{KH}$, Reno, NV) were used to introduce $50 \mathrm{nl}$ of donor cells every $50 \mu \mathrm{m}$ at depths from $600-100 \mu \mathrm{m}$ from the pial surface (total $400 \mu \mathrm{l}$ per injection site ) (13). Injection tracks spanned layers II though VI. Each mouse received four injections according to the following coordinates from bregma and midline $: \mathrm{A}=3.2, \mathrm{~L}=1.4 ; \mathrm{A}=2.7, \mathrm{~L}=1.6 ; \mathrm{A}=-0.8, \mathrm{~L}=$ $3.2 ; \mathrm{A}=-1.6, \mathrm{~L}=2.8^{13}$. Mice did not receive immunosuppression therapy.

\section{Behavioral Assessment}

Eight-direction maze test was initiated 8 weeks after transplantation and conducted as described elsewhere (9). The radial maze consisted of 8 symmetrical arms (25 cm long and $6 \mathrm{~cm}$ wide, with side walls $6 \mathrm{~cm}$ high), radiating from an octagonal central platform (10.5 cm diameter). The platform was enclosed by a wall $6 \mathrm{~cm}$ high. The floor of the maze was made of wood painted white, and the wall consisted of transparent Plexiglas. The apparatus was elevated $50 \mathrm{~cm}$ above the floor placed in a closed room where all visual cues were kept unchanged throughout the test trial. During the experiment, the maze was maintained in a constant orientation, and the experimenter stay constant position beside the maze and observed the performances of the mice. Completion of the radial maze entailed mouse running down and retrieving a food pellet of $15 \mathrm{mg}$ at the end of each arms. An arm entry was defined as the crossing of the four paws into an arm. Before each session of the test, mice were deprived of food until their body weight was reduced to $80-85 \%$ of the initial level. Pretraining started three days before test, in which each animal was placed in the central platform and allowed to explore and to consume a food pellet at the end of each arm. This was repeated daily for 3 consecutive sessions. During the test trail, only 4 arms were baited with food pellets and each mouse was given one daily trail for $6 \mathrm{~d} /$ week continued for 3 weeks. For each trial, two parameters, reference memory error (entry into the unbaited arms) and working memory error (repeated entry into the arms that had already been visited within a trial) were measured.

\section{Histology and Immunohistochemistry}

One week after the completion of behavioral testing (12 weeks after transplantation), all mice were deeply anesthetized with ketamine and xylazine and perfused transcardially with saline for 3 min and then with ice-cold $4 \%$ paraformaldehyde(PFA) in $0.1 \mathrm{M}$ PBS (pH7.4) for $30 \mathrm{~min}$. Then, the brains were removed and placed in PFA overnight. 30um thick Coronal or sagittal sections were cut on a vibratome(D. S. K microslicer, Japan) into series and placed free floating in PBS at $4^{\circ} \mathrm{C}$. Some sections of mouse brain transplanted with neurospheres or ES were stained by HE. Adjacent series of sections were stained with $\mathrm{Hu} \mathrm{C} / \mathrm{D}$, ChAT, serotonin, glutamate decarboxylase (GAD), GFP, glial fibrillary acidic protein (GFAP) ; and double-stained with ChAT-AP, serotonin-AP, ChAT-GFP, serotonin-GFP, GFAP-GFP. After extensive rinsed in PBS during continuous oscillation, sections were first incubated in $0.3 \%$ Triton $\mathrm{X}-100$ for $5 \mathrm{~min}$, then in $10 \%$ normal goat serum for $30 \mathrm{~min}$ at room temperature. This was followed by incubation in primary antibodies diluted in $10 \%$ normal goat serum at $4{ }^{\circ} \mathrm{C}$ for $48 \mathrm{hr}$ at the following dilutions : (1) rabbit polyclonal anti-ChAT IgG (1:1000;Sigma);(2)rabbit polyclonal anti-serotonin (1:5000;Sigma);(3) rabbit polyclonal anti-GAD (1:1000;Chemicon); rabbit polyclonal antiGFAP (1:800;Sigma);(5) mouse monoclonal anti-AP 
(1:50;Vector) ; (6) mouse monoclonal anti-GFP (1: 500;Molecular Probes);(7) mouse monoclonal anti-Hu C/D (1:100; Molecular Probes). Sections were also processed with omission of primary antibodies as negative controls; there was no nonspecific labeling. Sections were rinsed four times with PBS and incubated with the matching secondary antibodies conjugated with Alexa at $4{ }^{\circ} \mathrm{C}$ overnight:(1) goat polyclonal anti-rabbit IgG Alexa 11034 (1:1000;Molecular Probes) and (2) antimouse IgG Alexa 11031(1:1000; Molecular Probes). Sections were subsequently rinsed four times with PBS and mounted onto slides and coverslipped with Perma Fluor Aqueous mountant (Immunotech,Marseille,France). Fluorescent signals were detected and analyzed using a confocal laser-scanning microscope LSM (Olympus, Japan).

\section{Statistics}

The behavioral scores were analyzed using one-way analysis of variance (ANOVA) and t-test. Values of $\mathrm{p}<0.05$ were considered significant. Values in graph are expressed as mean \pm SEM.

\section{RESULTS}

Deafferentation of cholinergic system after ibotenic acid NBM lesioning

There were many ChAT-positive neurons and serotonin-positive neurons, and few GAD-positive
GABAergic neurons in NBM of the normal control mouse (Fig.1a, e, i). In the prefrontal and parietal cortices of the normal control mouse, many ChAT-positive fibers, serotonin-positive axons and GAD-positive neurons (Fig.1c, g, k) were recognized immunohistologically. In the NBM-lesioned mouse, the ChATpositive neurons, serotonin-positive neurons, and GADpositive neurons in the right NBM were reduced in number, especially the ChAT-positive neurons (Fig.1b, f, j). At the same time, the ChAT-positive fibers in the prefrontal and parietal cortices decreased remarkably, and the serotonin-positive axons slightly (Fig.1d, h), along with high AP co-expression (Fig. 2a, b). On the contrary, there were no changes in the GADpositive neurons in the cortex (Fig.1k, l).

\section{Neurospheres survival and differentiation mainly into} cholinergic neurons after transplantation into the cortex

The neurospheres grafts survived in the transplantation sites in the frontal and parietal cortices and gave rise to numerous ChAT-positive cells within and around the grafts as recognized by ChAT-GFP double stain (Fig. 3a). Moreover, we could find a few serotonin-positive cells (Fig. 3b), but neither GADpositive neurons nor GFAP-positive astrocytes were recognized by GAD-GFP and GFAP-GFP doublestaining indicating no cellular differentiation from the implanted neurospheres (Fig. 3c, d). The ChATpositive neurons and serotonin-positive neurons migrated and integrated into the cortex around the

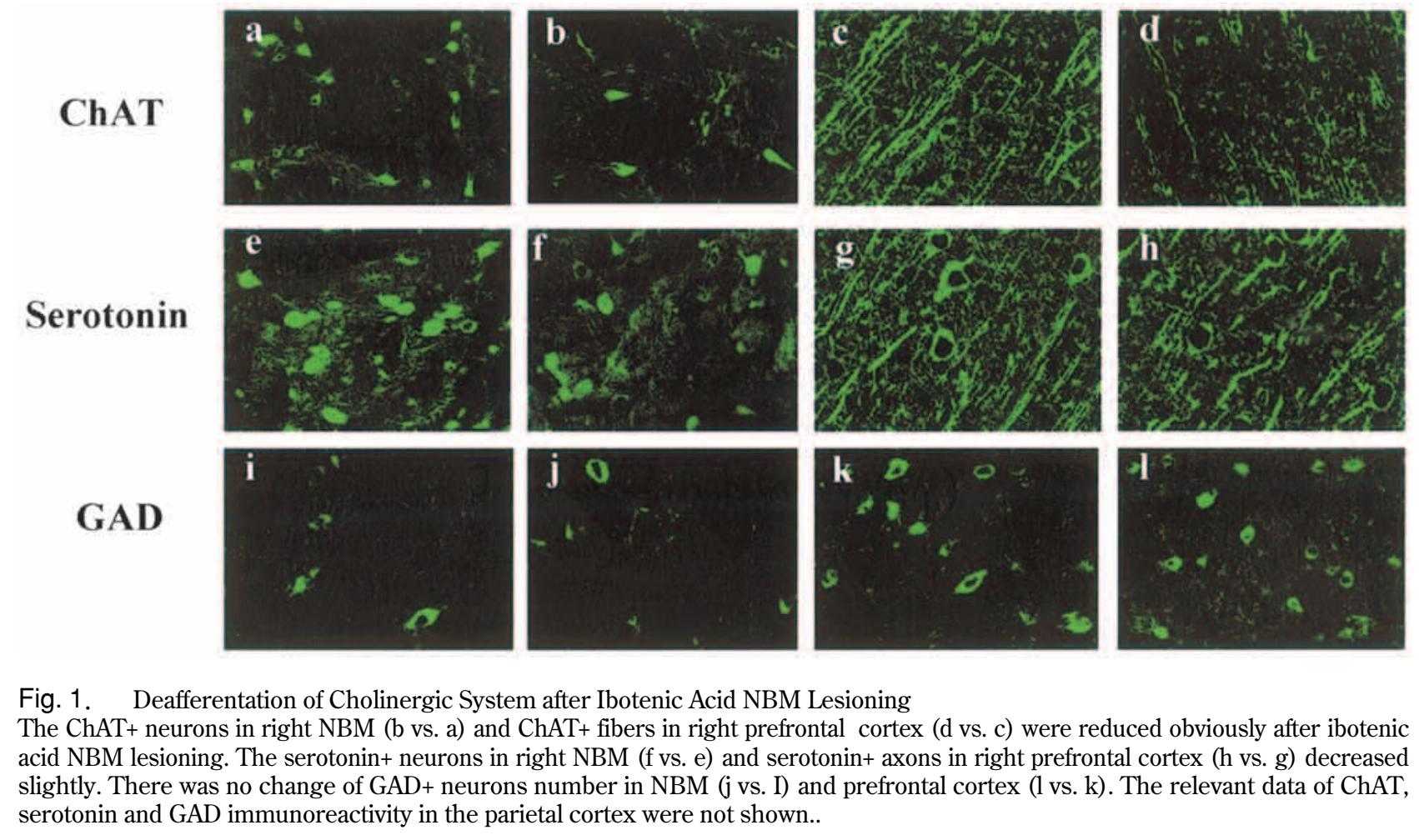



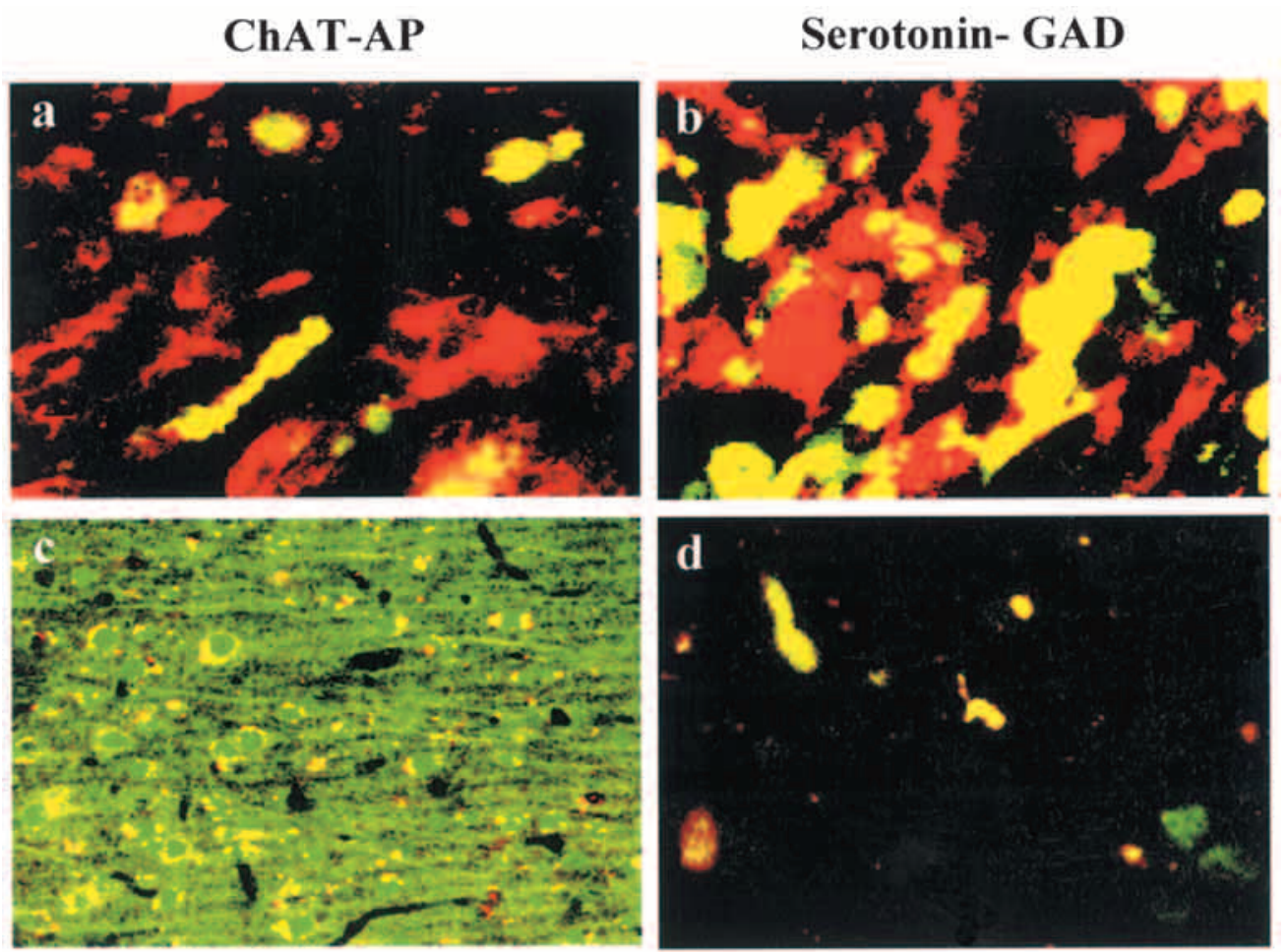

Fig. 2. Amyloid- $\beta$ Protein (AP) Changes after NBM Lesion and Neurospheres Transplantation

There were heavy AP (red) productions surrounding ChAT+ (blue) fibers (a) and serotonin+ (blue) axons (b) in right prefrontal cortex after NBM lesion. In the areas surrounding injection sites in prefrontal cortex, the ChAT+ neurons (c) and serotonin+ neurons (d) differentiated from neurospheres expressed slight AP. The relevant data in the parietal cortex were not shown.
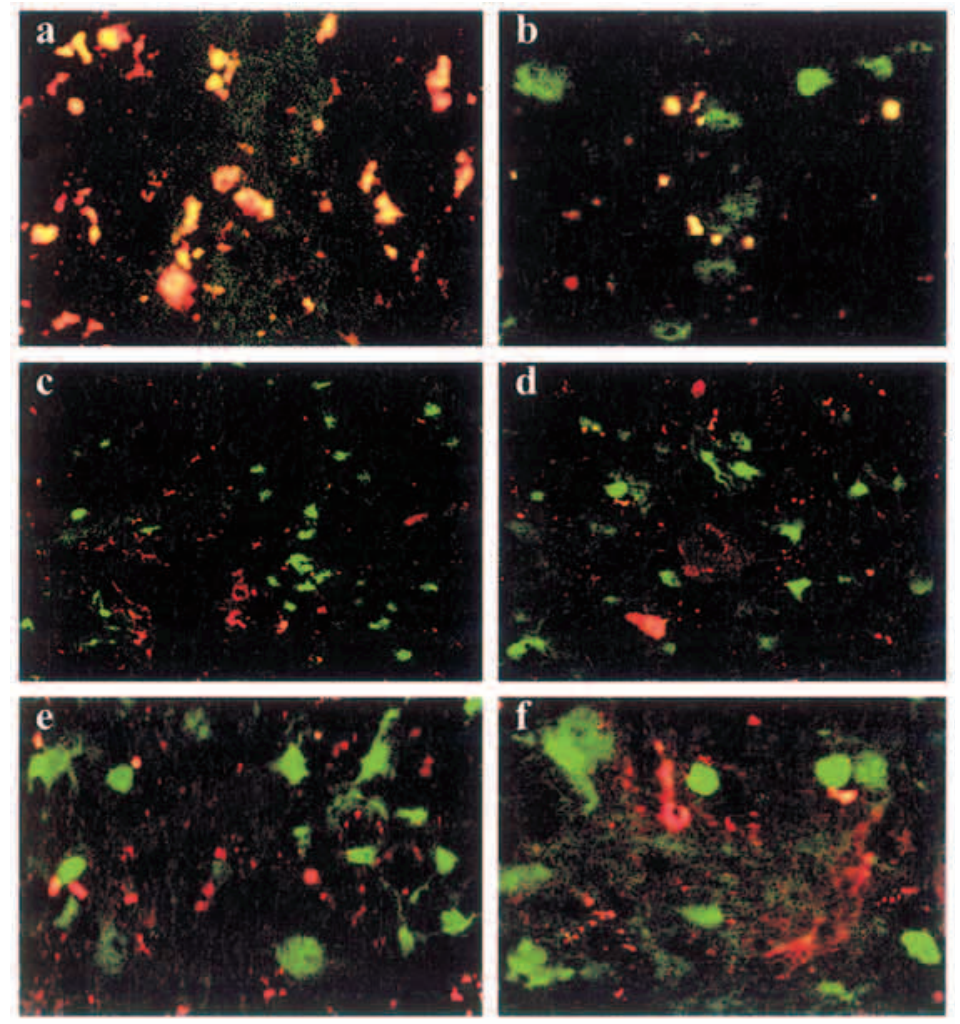

Fig. 3. Differentiation of Neurospheres and ES Cells after Grafted into Mouse Brain Cortex

There were a host of ChAT+ cells double stained by ChAT-GFP (a. ChAT, red; GFP, blue) and a very small number of serotonin+ cells labeled by serotonin-GFP (b. serotonin, red; GFP, blue) within and surrounding the neurospheres grafts in the right prefrontal cortex. GAD-GFP (c) and GFAP-GFP (d) double staining showed that the neurospheres produced no GABAergic (GAD+, red) neuron or GFAP+ (red) glia after transplanted into right prefrontal cortex. There were no Hu C/D-GFP (e) and GFAP-GFP (f) double stained cells in the sites of ES grafts indicted that the ES cells could not differentiate into neurons $(\mathrm{Hu} \mathrm{C} / \mathrm{D}$, red) or GFAP+ glias (GFAP, red) in right prefrontal cortex. The relevant data in the parietal cortex were not shown. 
injection tract and expressed less AP (Fig. 2 c, d).

\section{Development of ES cells after tansplantation into the cortex}

The ES cells grafts formed teratomas in all injection sites, with big ones in prefrontal cortex. Biopsy revealed that teratoma was the cause of epilepsy in two mice in our study. H\&E staining revealed characteristics of teratocarcinomas;namely, large tumor cells with hypertrophic and dividing nuclei (Fig. 4b). In contrast, the neurospheres developed into neurons with normal size and shape of the cell body and nucleus (Fig. 4a).
There was no neuronal or glia differentiation recognized as $\mathrm{Hu}$ C/D-GFP or GFAP-GFP double labeling immunoreactivity within and around the ES cells grafts. Our results indicated that the implanted ES cells did not migrate or differentiate, but proliferated into teratocarcinoma in situ.

\section{Eight-arm radial maze testing}

Figure 5 shows the mean scores of working memory errors and reference memory errors on eight-arm radial maze performance of all 5 groups of mice, with data
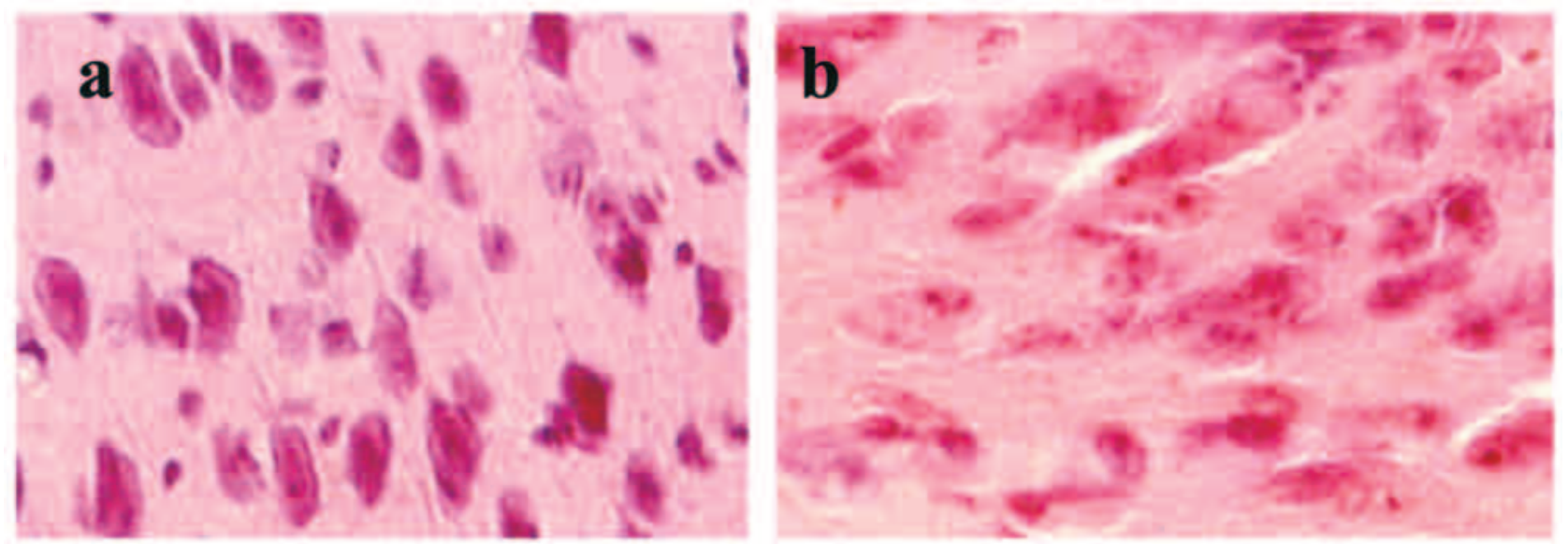

Fig. 4. HE Stain of Grafts of Neurospheres and ES Cells

HE stain revealed that neurospheres develop into neurons with normal size and shape of cell body and nuclear (a). In contrast, ES cells grew into teratocarcinomas with large tumor cells having hypertrophic and dividing nucleus(b).
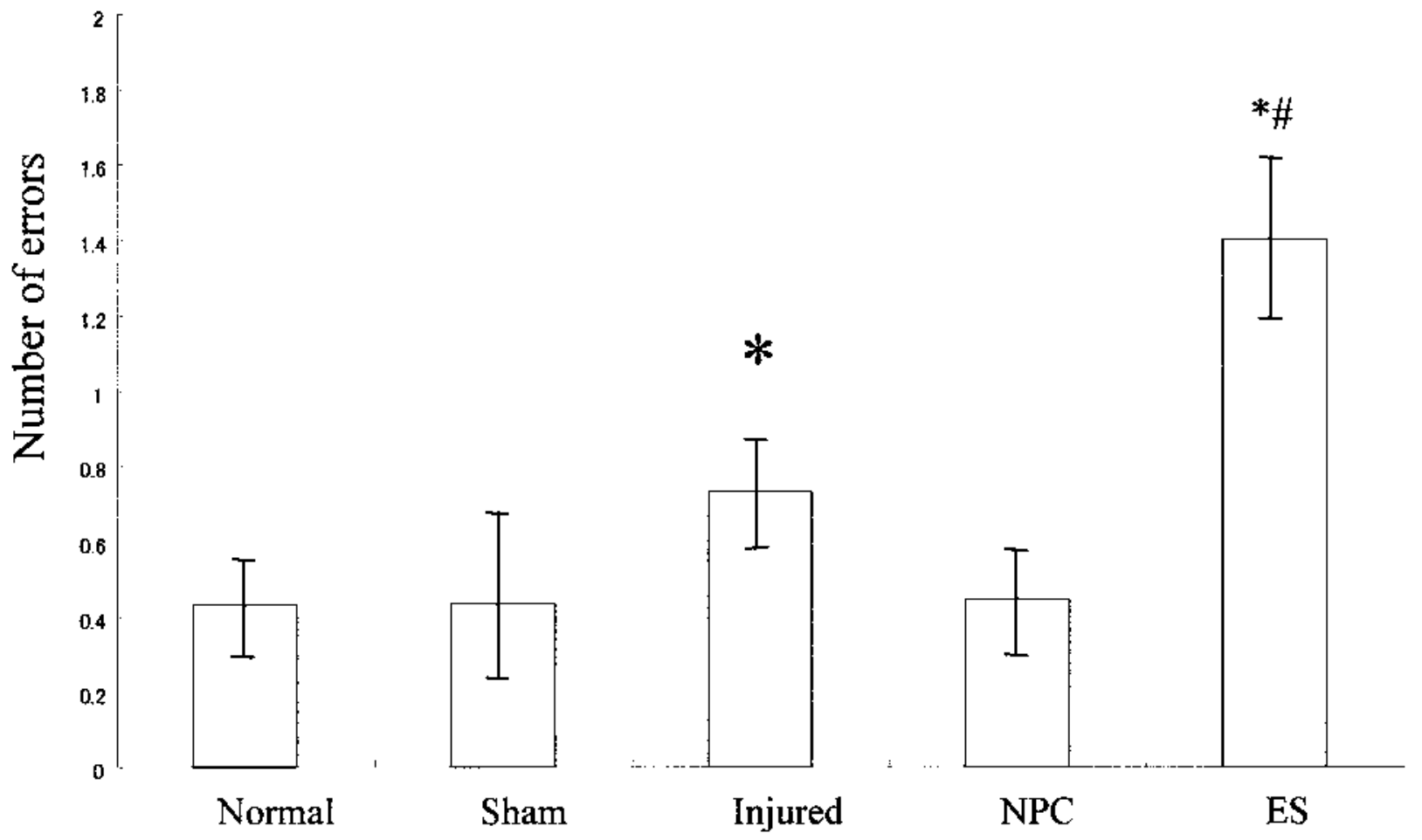

Fig. 5. Effects of Neurospheres and ES Cells on Eight-Arm Radial Maze Performance in Mice

Each column and vertical bar represents the mean \pm SEM of 18 trials. The statistical significance of injured group and neurospheres group vs. normal group are shown : ${ }^{\star} \mathrm{p}<0.01$; ES group vs. injured group are shown : \#p $<0.01$. 
averaged from 18 trials. In the NBM-lesioned mice, the working memory errors increased significantly $(t=6.13, p<0.001$ vs. the control group). In the mice transplanted with neurospheres, the scores were restored ( $t=0.307, p>0.05$, vs. the control group). With respect to the scores of mice transplanted with ES cells, the working memory deteriorated remarkably ( $\mathrm{t}=5.95, \mathrm{p}<0.001$ vs. normal group; $\mathrm{t}=6.46$, $\mathrm{p}<0.001$ vs. the NBM-lesioned group). There were no differences in the reference memory errors among the 5 groups $(P>0.05, F=0.1439, d . f .=4,62)$.

\section{DISCUSSION}

The results of our present investigation indicate that neurospheres transplanted into the prefrontal and parietal cortices produced numerous ChAT-positive neurons and significantly increased the performance level of the NBM-lesioned mice in the radial arm maze.

$\mathrm{AD}$ is characterized by progressive deterioration of memory and higher cortical functions that ultimately results in total degradation of the intellectual and mental activities. For nearly a quarter of century, the cholinergic hypothesis of $\mathrm{AD}$ has been valid that states; 1. the cholinergic neurons in the basal forebrain are severely affected during the course of the disease, detectable both histopathologically by loss of neurons, and neurochemically, by loss of the marker enzymes for acetylcholine synthesis (ChAT) and degradation, and 2. the resulting cerebral cholinergic deficit leads to memory loss. The NBM, which provides the major cholinergic input to the neocortex, undergoes profound neuron loss in $\mathrm{AD}$ (15-16). In the neocortex, there is a loss of cholinergic fibers and receptors and a decrease of both ChAT and acetylcholinesterase enzyme activities $(15,17)$. It was assumed that many neurotransmitter systems, including the serotoninergic and GABAergic, may be involved in the pathology of $\mathrm{AD}$ and dementia model made by ibotenic acid lesion of NBM (2, 4, $18,19)$. However, the outstanding pathologic findings are cholinergic neurons loss in NBM and cholinergic dysfunction in the frontal and parietal association neocortex (19-21). In the present study, we found that in the mouse prefrontal and dorsal parietal cortices, there were many ChAT-positive fibers, which is consistent with a previous study (22). After including the NBM lesion, the ChAT-positive terminals decreased evidently. The change of the serotonin+ axons was slight, and there was no change in the GAD-positive immunostaining. Ibotenic acid caused more prominent cholinergic neurons loss than it affected the serotoninergic and GABAergic (GAD+) neurons in NBM. The interpretation of our results could be that the basal forebrain cholinergic neurons appear to be significantly more vulnerable for toxicity (16).

The current drug therapies and other interventional approaches procedures for $\mathrm{AD}$ are still limited $(17,23)$. We are fortunate that neuroreplacement therapy is now available. Several recent studies have demonstrated that NPCs can integrate into the healthy host rodent brain in a cytoarchitecturally correct manner and differentiate into neurons and/or glia in a manner appropriate to the site of engrafment $(24,25)$. ES cells are pluripotent cells isolated from the inner cell mass of the preimplantation mouse blastocyst, which can differentiate into all kinds of cells. We have established a novel differentiation protocol of the ES cells to generate neurospheres that have forebrain characteristics via generating many functional cholinergic neurons in vitro and in vivo as described in the Materials and Methods. After transplantation into the frontal association cortex and barrel field of S1 cortex, the neurospheres differentiated mainly into ChAT-positive neurons, and the latter migrated into the surrounding cortex. We only found a few serotonin-positive neurons, and could scarcely find GFAP-positive glias within and around the grafts.

The memory deficit in $\mathrm{AD}$, which is characterized by recent memory disruption, has been attributed to cholinergic dysfunction in the neocortex. In theory, this memory loss would be ameliorated after the cholinergic system is restored. In our study, we used the partially (4 of 8 ) baited eight-arm radial maze task to evaluate the cognitive and mnemonic abilities in the mice. The mice were trained for one trial a day to eat pellet placed in the end of each baied arm, and the working memory error in the normal control group was nearly zero till the end of the trials. The effective performance in this task was based on two kinds of memory components;namely, working memory and reference memory. The former is a kind of information which incorporates the chosen arms in that trial and this disappears in a short time, and the latter is a kind of information about the configuration of the extra-maze (mainly visual) stimuli and should be retained until the next trial. The prefrontal and parietal association cortices, the major target areas of forebrain cholinergic neurons, have long been associated with high-level, "executive" processes, particularly a form of shortterm information storage described as "working" memory $(26,27)$. So, the working memory represents the current spatial memory. Our results revealed that the ibotenic 
acid-induced NBM lesion produced significant disruption of the working memory, which is consistent with another report (28). The transplanted neurospheres led to improvement of the working memory decline. The interpretation of this dramatic effect may be that the newly formed cholinergic neurons from the neurospheres grafts compensated for the cholinergic deficits in the NBM-lesioned mice.

Two reports state that the naive ES cells develop into dopaminergic neurons and cause behavioral restoration when grafted in low numbers into the striatum in a Parkinson rat model $(29,30)$. Another report indicated that the ES cells differentiated into neurons in the border zone of the ischemic lesion after being transplanted into the rat brain, meanwhile the ES cells produced highly malignant teratocarcinomas at the site of implantation without migration when grafted into the stroke mouse model (7). These different outcomes between xenotransplantation and homologous transplantation raise concerns about the safety of ES cells transplantation. Our results indicated that, the undifferentiated ES cells produced malignant teratomas in all implanted sites after being grafted into the mouse brain, with big ones in the prefrontal area, and that the working memory errors increased significantly as compare to the NBM-lesioned group.

\section{CONCLUSIONS}

Neurospheres can differentiated into the cholinergic neurons and restore the working memory decline after transplanted in a Alzheimer mouse model. In contrast, the transplantation of undifferentiated ES cells did not give any effect to the memory deficit of the NBM-lesioned mouse, but resulted in memory deteriorated due to the tumor formation.

\section{ACKNOWLEDGEMENTS}

This study was supported by Grants-in-aid for Scientific Research from the Japan Ministry of Education, Science, Sports and Culture (No. 16659389 and No. 17390402).

\section{REFERENCES}

1. Marin DB, Sewell MC, Schlechter A : Alzheimer's disease. Accurate and early diagnosis in the primary care setting. Geriatrics $57: 36-40,2002$
2. Rossner S, Schliebs R, Bigl V : Ibotenic acid lesion of nucleus basalis magnocellularis differentially affects cholinergic, glutamatergic and GABAergic markers in cortical rat brain regions. Brain Res 668 : 85-99, 1994

3. Selkoe DJ:Translating cell biology into therapeutic advances in Alzheimer's disease. Nature 399: A2331, 1999

4. Auld DS, Kornecook TJ, Bastianetto S, Quirion $\mathrm{R}$ : Alzheimer's disease and the basal forebrain cholinergic system: relations to $\beta$-amyloid peptides, cognition, and treatment strategies. Prog Neurobiology 68 : 209-245, 2002

5. Lee VM, Goedert M, Trojanowski JQ: Neurodegenerative tauopathies. Annu Rev Neurosci 24: 1121-1159, 2001

6. Gauthier S:Advances in the pharmacotherapy of Alzheimer's disease. Can Med Assoc J 166, 6166-23, 2002

7. Erdo F, Buhrle C, Blunk J, Hoehn M, Xia Y, Fleischmann B, Focking M, Kustermann E, Kolossov E, Hescheler J, Hossmann KA, Trapp T: Host-dependent tumorigenesis of embryonic stem cell transplantation in experimental stroke. J Cereb Blood Flow Metab 23 : 780-785, 2003

8. Helene J, Jason Y, Elisabeth A, Patricia MP, Sarah S, Luc G, Sophie C, Eliane M, Jean-Christophe C: Transplantation of neurospheres after granule cell lesions in rats:cognitive improvements despite no long-term immunodetection of grafted cells. Behav Brain Res 143 : 1771-91, 2003

9. Hodges H:Maze procedure:the radial-arm and water maze compared. Brain Res Cogn Brain Res $3: 167-181,1996$

10. Jeong SW, Chu K, Jung KH, Kim SU, Kim M, Roh JK : Human Neural Stem Cell Transplantation Promotes Functional Recovery in Rats With Experimental Intracerebral Hemorrhage. Stroke 24: 2003

11. Liker MA, Petzinger GM, Nixon $\mathrm{K}, \mathrm{McNeill} \mathrm{T}$, Jakowec MW : Human neural stem cell transplantation in the MPTP-lesioned mouse. Brain Res $971:$ 168-177, 2003

12. Nakatomi H, Kuriu T, Okabe S, Yamamoto S, Hatano O, Kawahara N, Tamura A, Kirino T, Nakafuku M : Regeneration of hippocampal pyramidal neurons after ischemic brain injury by recruitment of endogenous neural progenitors. Cell 110 : 429-441,2002.

13. Fricker-Gates RA, Shin JJ, Tai CC, Catapano LA, Macklis JD : Late-stage immature neocortical neurons reconstruct interhemispheric and from 
synaptic contacts with increased efficiency in adult mouse cortex targeted.The Journal of Neuroscience 22 : 4045-4056, 2002

14. Niwa H, Masui S, Chambers I, Smith AG, Miyazaki J : Phenotypic complementation established requirements for specific POU domain and generic transactivation function of Oct- $3 / 4$ in embryonic stem cells. Mol Cell Biol 22: 1526-1536, 2002

15. German DC, Yazdani U, Speciale SG, Pasbakhsh P, Games D, Liang CL:Cholinergic neuropathology in a mouse model of Alzheimer's disease. J Comp Neurol 462 : 371-381, 2003

16. Terry AV Jr, Buccafusco JJ : The cholinergic hypothesis of age and Alzheimer's disease-related cognitive deficits: recent challenges and their implications for novel drug development. Pharmacol Exp Ther 306 : 821-827, 2003

17. Akhondzadeh S, Noroozian M:Alzheimer's disease: Pathophysiology and Pharmacotherapy Drugs 5 : 1062-1069, 2002

18. Lanctot KL, Herrmann N, Mazzotta P : Role of serotonin in the behavioral and psychological symptoms of dementia. J Neuropsychiatry Clin Neurosci $13: 5-21,2001$

19. Lucas-Meunier E, Fossier P, Baux G, Amar M: Cholinergic modulation of the cortical neuronal network. Pflugers Arch 446 : 17-29, 2003

20. Cullen KM, Halliday GM : Neurofibrillary degeneration and cell loss in the nucleus basalis in comparison to cortical Alzheimer pathology. Neurobiol Aging 19 : 297-306, 1998

21. Jope RS, Song L, Powers RE:Cholinergic activation of phosphoinositide signaling is impaired in Alzheimer's disease brain. Neurobiol Aging 18: 111-120, 1997
22. Kitt CA, Hohmann C, Coyle JT, Price DL: Cholinergic innervation of mouse forebrain structures. J Comp Neurol 341 : 117-29, 1994.

23. Bachurin SO:Medicinal chemistry approaches for the treatment and prevention of Alzheimer's disease. Med Res Rev 23 : 48-88, 2003

24. Snyder EY, Yoon C, Flax JD, Macklis JD : Multipotent neural precursors can differentiate toward replacement of neurons undergoing targeted apoptotic degeneration in adult mouse neocortex. Proc Natl Acad Sci USA 94 : 1166311668, 1997

25. Whittemore SR, Snyder EY : Physiological relevance and functional potential of central nervous systemderived cell lines. Mol Neurobiol 12:13-38,1996

26. Goldman-Rakic PS : Cellular basis of working memory. Neuron 14 : 477-485, 1995

27. Miller EK:The prefrontal cortex:complex neural properties for complex behavior. Neuron 22:15-7, 1999

28 Belleville S, Peretz I, Malenfant D : Examination of the working memory components in normal aging and in dementia of the Alzheimer type. Neuropsychologia 34 : 195-207, 1996

29. Bjorklund LM, Sanchez-Pernaute R, Chung S, Andersson T, Chen IY, McNaught KS, Brownell AL, Jenkins BG, Wahlestedt C, Kim KS, Isacson O: Embryonic stem cells develop into functional dopaminergic neurons after transplantation in a Parkinson rat model. Proc Natl Acad Sci U S A $99: 2344-2349,2002$

30. Deacon T, Dinsmore J, Costantini LC, Ratliff J, Isacson $\mathrm{O}$ : Blastula-stage stem cells can differentiate into dopaminergic and serotonergic neurons after transplantation. Exp Neurol 149 : 28-41,1998 